\title{
Current source density approaches improve spatial resolution in event related potential analysis in people with Parkinson's disease
}

\author{
Conor Fearon \\ Trinity College Dublin, Ireland \\ John Butler \\ Technological University Dublin, john.s.butler@tudublin.ie \\ Saskia M. Waechter \\ Trinity College Dublin, Ireland
}

See next page for additional authors

Follow this and additional works at: https://arrow.tudublin.ie/scschmatart

Part of the Mathematics Commons, Musculoskeletal, Neural, and Ocular Physiology Commons, and the Neurosciences Commons

\section{Recommended Citation}

Fearon, C., Butler, J.S., Waechter, S.M., Killane, I., Reilly, R.B., Lynch, T., Current Source Density Approaches Improve Spatial Resolution in Event Related Potential Analysis in People with Parkinson's Disease, Clinical Neurophysiology (2019), doi: 10.1016/j.clinph.2019.06.232

This Article is brought to you for free and open access by the School of Mathematics at ARROW@TU Dublin. It has been accepted for inclusion in Articles by an authorized administrator of ARROW@TU Dublin. For more information, please contact arrow.admin@tudublin.ie, aisling.coyne@tudublin.ie,gerard.connolly@tudublin.ie.

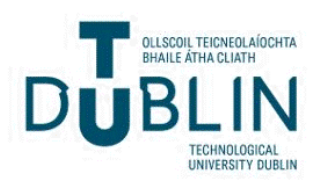




\section{Authors}

Conor Fearon, John Butler, Saskia M. Waechter, Isabelle Killane, Richard B. Reilly, and Timothy Lynch 


\section{Accepted Manuscript}

Letter to the Editor

Current Source Density Approaches Improve Spatial Resolution in Event Related Potential Analysis in People with Parkinson's Disease

Conor Fearon, John S. Butler, Saskia M. Waechter, Isabelle Killane, Richard B. Reilly, Timothy Lynch

PII: S1388-2457(19)31154-X

DOI: https://doi.org/10.1016/j.clinph.2019.06.232

Reference: CLINPH 2008919

To appear in: Clinical Neurophysiology

Accepted Date: $\quad 4$ June 2019

Please cite this article as: Fearon, C., Butler, J.S., Waechter, S.M., Killane, I., Reilly, R.B., Lynch, T., Current Source Density Approaches Improve Spatial Resolution in Event Related Potential Analysis in People with Parkinson's Disease, Clinical Neurophysiology (2019), doi: https://doi.org/10.1016/j.clinph.2019.06.232

This is a PDF file of an unedited manuscript that has been accepted for publication. As a service to our customers we are providing this early version of the manuscript. The manuscript will undergo copyediting, typesetting, and review of the resulting proof before it is published in its final form. Please note that during the production process errors may be discovered which could affect the content, and all legal disclaimers that apply to the journal pertain. 


\section{Current Source Density Approaches Improve Spatial Resolution in Event Related Potential Analysis in People with Parkinson's Disease}

Conor Fearon ${ }^{* 1,2,3}$, John S. Butler ${ }^{* 1,4,5}$, Saskia M. Waechter ${ }^{1,2}$, Isabelle Killane ${ }^{1,2,6}$, Richard B. Reilly ${ }^{1,2,5}$ \& Timothy Lynch ${ }^{3}$

${ }^{1}$ Trinity Centre for Bioengineering, Trinity College, The University of Dublin, Dublin 2, Ireland

${ }^{2}$ School of Engineering, Trinity College, The University of Dublin, Dublin 2, Ireland

${ }^{3}$ Dublin Neurological Institute at the Mater Misericordiae University Hospital, Dublin

7, Ireland

${ }^{4}$ School of Mathematical Sciences, Dublin Institute of Technology, Kevin Street, Dublin, Ireland

${ }^{5}$ School of Medicine, Trinity College, The University of Dublin, Dublin 2, Ireland

${ }^{6}$ School of Mechanical and Design Engineering, Dublin Institute of Technology, Bolton Street, Dublin, Ireland

\section{Corresponding authors:}

- Timothy Lynch, Centre for Brain Health, Dublin Neurological Institute at the Mater Misericordiae University Hospital, 57 Eccles Street, Dublin 7, tlynch@dni.ie

- Richard B. Reilly, Trinity Centre for Bioengineering, the School of Medicine and the School of Engineering, Trinity College Dublin, Ireland, rbreilly@tcd.ie

*C. Fearon and J.S. Butler contributed equally to the paper. 
We read with great interest the recent article by Maidan and colleagues (Maidan et al. 2019). Using an auditory oddball task while standing and walking on a treadmill, they conducted an event-related potential analysis in 10 people with Parkinson's disease, 10 older adults and 11 young adults, with particular focus on P300 amplitude and latency. In all three groups, the P300 latency increased while walking compared to standing. The reduced P300 amplitude while walking was only seen in the Parkinson's group. Given the associations between the P300 and attentional mechanisms in response to novel stimuli, the authors hypothesize impaired recruitment of attentional networks during dual-tasking in people with Parkinson's disease.

The amplitude and topography of the P300 is impacted by even simple motor responses (Salisbury et al. 2001). We have previously described results of a visual oddball in 20 people with Parkinson's disease with and without freezing of gait while seated (Butler et al. 2017). Employing a standard event-related potential analysis (similar to that in Maiden et al.), we initially demonstrated differences in P300 amplitudes between Parkinson's patients with and without freezing of gait (Figure 1A). However, the scalp distribution of energy centered around the P300 showed a different story (Figure 1B). The non-freezing group displayed a well-defined signal focus over centroparietal area, as is often seen in P300 in healthy subjects. The energy in the freezing group, however, was more diffuse, with spread towards the right frontal area (solid arrow), raising the possibility that the signal seen was a combination of two separate sources the P300 and motor response.

This motivated re-analysis of our data, using a current source density (CSD) analysis. The CSD is a Laplacian transformation which performs a spatial high pass filter on the ERP data, reducing interference from remote sources and current diffusions through the skull and, hence, improves spatial resolution (Kayser and Tenke 2006). The CSD topoplots show that the non-freezing group maintain a localized response over centroparietal areas (Figure 1C). The response of the freezing group, on the other hand, clearly consists of two separate signal foci (open arrows), a centroparietal response, similar to the non-freezers but also positive activity in the right frontal 
area (and negative activity in the left frontal area) which is distinct from this centroparietal positivity (CPP). We have demonstrated that this frontal signal is a movement-related cortical potential which precedes voluntary movement (a button press in this case) and reflects activity in the motor cortex, premotor area (PMA) and supplementary motor area (SMA) contralateral to the side of the body in which the movement occurs (Shibasaki and Hallett 2006). This movement-related cortical potential was significantly larger in the freezing group compared to the non-freezing group and interference from this signal had led to underestimation of the amplitude of the P300 in the initial ERP analysis. Re-analysis of the CPP (the equivalent of the P300), using the CSD approach, revealed that there was in fact no difference in this potential between groups (Figure 1D).

In light of this, we wonder whether Maidan and colleagues considered interference from these movement related cortical potentials in interpreting their results. In general, we propose that a CSD approach should be considered in analysis of event related potentials in people with Parkinson's disease.

Figure 1. A) ERP analysis showing the mean and standard error of the mean P300 responses for non-freezers (FOG-, blue, $N=10$ ) and freezers (FOG + , grey, $N=10$ ). Note apparent significant difference between groups. The solid black line indicates the stimulus onset, the dashed vertical lines indicate the mean response time for the FOG- (blue) group and FOG+ (grey) group; B) The mean ERP scalp distribution for the FOG-(top) group and FOG+ (bottom) group. Solid arrow indicates diffuse $P 300$ distribution, with spread towards the right frontal area; C) The mean CSD scalp distribution for the FOG- (top) group and FOG+ (bottom) group for comparison. Open arrows indicate two separate sources within the diffuse energy signal seen in the ERP topoplot. D) Re-analysis of the mean and standard error of the mean centroparietal positivity (CPP) responses for FOG- (blue) and FOG+ (grey). Note lack of significant difference between groups.

\section{Conflict of interest statement}

None of the authors have potential conflicts of interest to be disclosed.

There are no funding sources relevant to this paper. 


\section{References}

Butler JS, Fearon C, Killane I, Waechter SM, Reilly RB, Lynch T. Motor preparation rather than decision-making differentiates Parkinson's disease patients with and without freezing of gait. Clin Neurophysiol. 2017;128:463-71.

Kayser J, Tenke CE. Principal components analysis of Laplacian waveforms as a generic method for identifying ERP generator patterns: I. Evaluation with auditory oddball tasks. Clin Neurophysiol. 2006;117:348-68.

Maidan I, Fahoum F, Shustak S, Gazit E, Patashov D, Tchertov D, et al. Changes in event-related potentials during dual task walking in aging and Parkinson's disease. Clin Neurophysiol. 2019;130:224-30.

Salisbury DF, Rutherford B, Shenton ME, McCarley RW. Button-pressing affects P300 amplitude and scalp topography. Clin Neurophysiol. 2001;112:1676-84.

Shibasaki $\mathrm{H}$, Hallett M. What is the Bereitschaftspotential? Clin Neurophysiol. 2006;117:2341-56. 


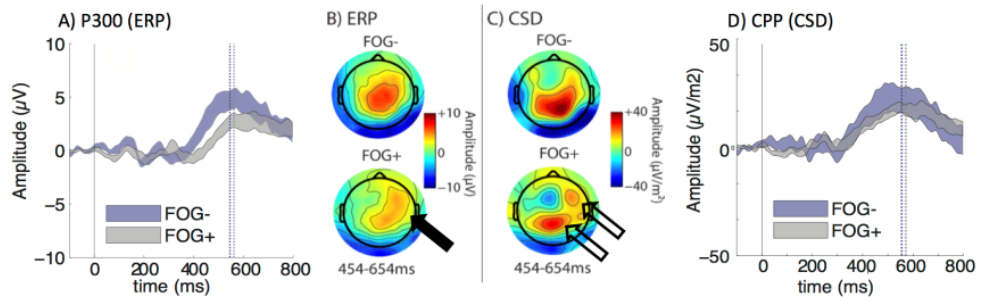

